\title{
Lack of Effect of Intravenous Administration on Time to Respond to Azathioprine for Steroid-Treated Crohn's Disease
}

\author{
WILLIAM J. SANDBORN,* WILLIAM J. TREMAINE,* DOUGLAS C. WOLF, ${ }^{\prime}$ STEPHAN R. TARGAN, ${ }^{\S}$

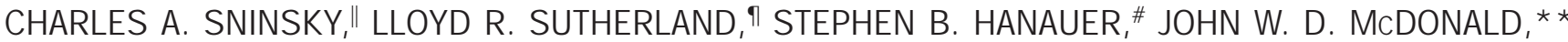 \\ BRIAN G. FEAGAN, ** RICHARD N. FEDORAK, \\ DENNIS C. MAYS, IIII JAMES J. LIPSKY, III SUSAN GORDON, "१ CHRISTI S. KLEOUDIS, "१ \\ and ROBERT H. MURDOCK, Jr., "ा for the NORTH AMERICAN AZATHIOPRINE STUDY GROUP \\ * Division of Gastroenterology, Mayo Clinic, Rochester, Minnesota; ${ }^{\ddagger}$ Atlanta Gastroenterology Associates, Atlanta, Georgia; ${ }^{\S}$ Department \\ of Gastroenterology, Cedars Sinai Medical Center, Los Angeles, California; "Department of Gastroenterology, University of Florida, \\ Gaines ville, Florida; "Department of Gastroenterology, University of Calgary, Calgary, Alberta, Canada; \#Department of Gastroenterology, \\ University of Chicago, Chicago, Illinois; ** Department of Gastroenterology, University of Western Ontario, London, Ontario, Canada;

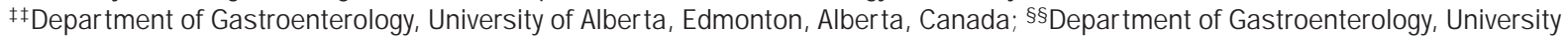 \\ of North Carolina, Chapel Hill, North Carolina; IIIClinical Pharmacology Unit, Mayo Clinic, Rochester, Minnesota; and " ${ }^{\uparrow} \mathrm{Glaxo}$ Wellcome, \\ Research Triangle Park, North Carolina
}

Background \& Aims: Azathioprine is effective for Crohn's disease but acts slowly. A loading dose may decrease the time to response. Methods: A placebo-controlled study was conducted in patients with active Crohn's disease despite prednisone treatment. Patients were randomized to a 36-hour infusion of azathioprine, 40 $\mathrm{mg} / \mathrm{kg}$ (51 patients), or placebo (45 patients) followed by oral azathioprine, $2 \mathrm{mg} / \mathrm{kg}$, for 16 weeks. Prednisone was tapered over 5 weeks. The primary outcome measure was complete remission at week 8 , defined by discontinuation of prednisone and a Crohn's Disease Activity Index of $\leq 150$ points. Erythrocyte concentrations of the azathioprine active metabolite, 6-thioguanine nucleotide, were measured. Results: At week 8,13 patients $(25 \%)$ were in complete remission in the azathioprine-loaded group compared with 11 patients $(24 \%)$ in the placebo group. The frequency of complete remission did not increase after 8 weeks in either group. Both groups achieved steady state of 6 -thioguanine nucleotide by week 2 , and no differences were found in mean concentrations between the groups. There were no significant differences in the frequency of adverse events between the groups. Conclusions: A loading dose does not decrease the time to response in patients with steroid-treated Crohn's disease beginning azathioprine therapy. Steady state of erythrocyte 6 -thioguanine nucleotide and complete response occurred earlier than previously reported.

$\mathrm{n}$ the treatment of Crohn's disease, 6-mercaptopurine (6M P) and its prodrug azathioprine (AZA) are efficacious. ${ }^{1-8} \mathrm{H}$ owever, widespread use of these medications is limited by the perception that they have a slow onset of action. Present et al. ${ }^{4}$ reported that the mean time to response in patients with Crohn's disease treated with $6 \mathrm{MP}$ was 3.1 months and that $19 \%$ of responders required 4 months or more of treatment before improvement was observed. In a meta-analysis of all placebocontrolled trials of AZA/6M P for Crohn's disease, Pearson et al. ${ }^{8}$ reported that a consistent clinical benefit for AZA/6M P therapy was observed only after 17 weeks or more of therapy. The reason that AZA/6MP may act slowly is unclear. Some small pharmacokinetic studies have reported that the active metabolites of AZA/6M P, the 6-thioguanine nucleotides (6TGN), have a long half-life resulting in slow accumulation in red blood cells (RBCS) and other body tissues and the need for prolonged treatment to reach steady state.,10 Other studies have reported that RBC $6 T$ GN steady state is reached within 14-21 days in most patients. ${ }^{11,12}$ These pharmacological observations raised the possibility that administration of a loading dose of AZA or 6MP could accelerate their onset of action. An open-label pilot study reported that patients with refractory Crohn's disease treated with an intravenous (IV) loading dose of AZA (1800 mg [20-44 $\mathrm{mg} / \mathrm{kg}$ ] over 36 hours) achieved a steady state of RBC $6 T$ TN within 3 days and experienced rapid clinical

Abbreviations used in this paper: AZA, azathioprine; IBDQ, Inflammatory Bowel Disease Questionnaire; 6MP, 6-mercaptopurine; 6TGN, 6 -thioguanine nucleotides; TPMT, thiopurine methyltransferase; WBC, white blood cell. () 1999 by the American Gastroenterological Association 0016-5085/99/\$10.00 
benefit. ${ }^{13}$ Based on these preliminary results, we conducted a 16-week placebo-controlled trial of an IV AZA loading dose of $40 \mathrm{mg} / \mathrm{kg}$ in patients with active steroid-treated Crohn's disease beginning oral A ZA treatment.

\section{Patients and Methods}

\section{Selection of Patients}

Thestudy was performed between September 1996 and $\mathrm{N}$ ovember 1997. Eligible patients were at least 18 years of age and had active steroid-treated Crohn's disease, as defined by a score of 150-450 on the Crohn's Disease Activity Index (CDAI) and treatment with prednisone at a dose of $\geq 20$ $\mathrm{mg} /$ day for $\geq 4$ weeks. The CDAl assesses 8 variables: the number of liquid stools, extent of abdominal pain, general well-being, occurrence of extraintestinal symptoms, need for antidiarrheal drugs, presence of abdominal masses, hematocrit, and body weight. ${ }^{14}$ Scores can range from 0 (no active disease) to approximately 600 (severe disease). Scores of 150-450 are associated with disease that is mildly to moderately active. Scores of $<150$ indicate remission.

Eligible patients had disease that involved the ileum, ileocolon, or the colon, verified previously by colonoscopy, barium enema, or small bowel follow-through. Patients with currently present fistulas involving adjacent loops of bowel (enteroenteric fistulas) or the perianal region were eligible. In addition, patients had to have normal metabolism of AZA as defined by normal activity of the major catabolic enzyme for AZA, thiopurine methyltransferase (TPMT). ${ }^{15}$ The following patients were not eligible: those with active Crohn's disease isolated to the duodenum, jejunum, or perianal region; those with currently present ileostomy or col ostomy, septic complica tions, abscess, perforation with acute abdomen, or fistulas involving the skin, bladder, or vagina; those who had astricture of the ileum or colon resulting in symptomatic obstruction (confirmed by endoscopic or radiological studies) within 6 months; those who had undergone resection of more than 100 $\mathrm{cm}$ of the ileum; or those requiring immediate surgery. Before the study, no patient recei ved biotechnology therapies within 6 months, immune modifier drugs within 3 months, or antibiotics or mesalamine within 2 weeks, si milar to the criteria used in other controlled trials of medical therapy for active Crohn's disease. ${ }^{16-18}$ Patients with a history of cancer of any type, definite dysplasia of the colon within 5 years, or clinically significant renal or hepatic disease were ineligible, as were pregnant or breast-feeding women, patients who were allergic to 6MP or AZA, and patients receiving allopurinol. The study was approved by the institutional review board at each center, and all participants gave written informed consent.

\section{Study Medication}

The IV AZA loading dose of $40 \mathrm{mg} / \mathrm{kg}$ over 36 hours was chosen based on the preliminary data from a pilot study showing that an IV AZA loading dose of 20-44 mg/ $\mathrm{kg}$ was safe and of apparent benefit ${ }^{13}$ and data from phase I studies of continuous infusion 6MP for chemotherapy that showed significant toxicity with $6 \mathrm{MP}$ doses of $50 \mathrm{mg} \cdot \mathrm{m}^{2} \cdot \mathrm{h}^{-1}$ for 48 and 60 hours, and minimal toxicity with doses of $50 \mathrm{mg} \cdot \mathrm{m}^{2}$. $\mathrm{h}^{-1}$ for 12,24 , and 36 hours. ${ }^{19,20}$ Assuming a body surface of $1.73 \mathrm{~m}^{2}$ and a body weight of $70 \mathrm{~kg}$ for the average adult, and a conversion factor of 2.07 for comparing 6M P with AZA (given $88 \%$ conversion of $A Z A$ to $6 \mathrm{MP}$, and a molecular weight ratio of 0.55$), 6 \mathrm{MP}$ infusions at $50 \mathrm{mg} \cdot \mathrm{m}^{2} \cdot \mathrm{h}^{-1}$ for $12,24,36,48$, and 60 hours would be comparable with $31,61,92,123$, and $153 \mathrm{mg} / \mathrm{kg}$. Thus, the AZA loading dose of $40 \mathrm{mg} / \mathrm{kg}$ used in the present study is comparable with the $6 \mathrm{MP}$ dose of $50 \mathrm{mg}$. $\mathrm{m}^{2} \cdot \mathrm{h}^{-1}$ for $12-24$ hours, at which only minimal toxicity occurred.

U nblinded study pharmacists at each center prepared the IV infusions ( $A Z A$ or placebo). For patients treated with $A Z A$, the pharmacist determined the total amount of $A Z A$ to be administered (based on a total AZA dose of $40 \mathrm{mg} / \mathrm{kg}$ ), divided the total amount by 3 , reconstituted the appropriate number of 100 -mg vials of AZA for injection (I muran; Glaxo W ell come, Research Triangle Park, N C), added the appropriate amount of reconstituted AZA into an empty 1000-mL Viaflex bag (Baxter M edical, R ound Lake, IL), and added normal sal ine to obtain a total infusion volume of $600 \mathrm{~mL}$. For patients treated with placebo, the pharmacist added $3 \mathrm{~mL}$ of Multi-Vitamins for Infusion (Schein Pharmaceuticals, Inc., Florham, N J) and 597 $\mathrm{mL}$ of normal saline into an empty $1000-\mathrm{mL}$ Viaflex bag (Baxter M edical). Patients then received 3 consecutive $600-\mathrm{mL}$ infusions of study medication (AZA or placebo), each administered continuously at a rate of $50 \mathrm{~mL} / \mathrm{h}$ for 12 hours. Both reconstituted AZA and multivitamins had a similar yellowish appearance designed to blind patients, investigators, and medical personnel caring for the patient to the treatment allocation. To further maintain blinding, the study pharmacist applied opaque sl eeves to the infusion bags.

The oral AZA formulation used is a scored tablet containing $50 \mathrm{mg}$ of AZA (I muran, G laxo W ellcome). The total daily dose of oral AZA was based on body weight $(2.0 \mathrm{mg} / \mathrm{kg})$, rounded upward to the nearest $25 \mathrm{mg}$. This dose of oral AZA, which was at the lower end of the range of $A Z A$ doses previously reported to be effective for Crohn's disease, ${ }^{8}$ was chosen to give a margin of safety in patients who had just completed an IV loading dose of AZA of $40 \mathrm{mg} / \mathrm{kg}$. The entire dose of AZA, $2.0 \mathrm{mg} / \mathrm{kg}$, was administered as a single daily dose beginning on day 3 of the study. If patients devel oped laboratory abnormal ities consistent with hepatotoxicity (level s of aspartate aminotransferase $>5 \times$ normal or alkaline phosphatase $>3 \times$ normal), leukopenia (total white blood cell count $<3.0 \times 10^{9} / \mathrm{L}$ ), or thrombocytopenia (platelet count $<100 \times 10^{9} / \mathrm{L}$ ), then AZA administration was discontinued until the abnormal ity resolved, and $A Z A$ was restarted at $1.0 \mathrm{mg} \cdot \mathrm{kg}^{-1} \cdot$ day $^{-1}$. Decisions regarding AZA discontinuation or dose adjustments in patients who experienced infection, fever, rash, arthralgias, malaise, and nausea were handled on a case-by-case basis. If patients developed pancreatitis or malignancy, AZA administration was discontinued. Compliance with oral AZA therapy was determined by pill count. 


\section{Prednisone Therapy}

At the time of enrollment into the study (2 weeks before randomization), all patients had their prednisone dose adjusted to $20 \mathrm{mg} /$ day, similar to the method reported previously by Feagan. ${ }^{21}$ Thus, patients taking prednisone at a dose $>20 \mathrm{mg} /$ day had their dose immediately reduced to 20 $\mathrm{mg} /$ day (regardless of the duration of steroid therapy or the duration of time at the current steroid dose); and patients taking $20 \mathrm{mg}$ prednisone daily continued at that dose. For 2 weeks after randomization, no attempt was made to decrease the prednisone dose. After the first follow-up visit (at week 2), the daily prednisone dose was decreased by $5 \mathrm{mg}$ each week. Prednisone was discontinued at the beginning of week 6 . In subjects whose condition worsened (increase in the CDAI > 100 points above baseline or CDAI > 450), the prednisone dose was increased to $40 \mathrm{mg} /$ day for 1 week and decreased by 5 mg each week until prednisone was discontinued.

\section{Design of the Study}

The study was a randomized, double-blind, placebocontrolled trial performed at 16 centers in the U nited States and Canada. Patients were stratified according to treatment center and randomized separately in permuted blocks of 2 by the unblinded study pharmacist at each center using a computer-generated randomization scheme. The blinded 36hour infusion of $40 \mathrm{mg} / \mathrm{kg} \mathrm{AZA}$ or placebo was followed by 16 weeks of open therapy with oral AZA, $2.0 \mathrm{mg} \cdot \mathrm{kg}^{-1} \cdot$ day $^{-1}$. The study duration of 18 weeks (2-week period of equilibration after standardization of prednisone and withdrawal of mesalamine and antibiotics, and then 16 weeks of AZA therapy) was based on the hypothesis that an IV AZA loading dose would accel erate the onset of action of AZA (making a long-term trial unnecessary) and on a meta-analysis of previous studies of oral AZA for active Crohn's disease, which showed that the odds ratio for response became significant with a study duration of 17 weeks. $^{8}$

At entry, each patient's demographic characteristics, medical history, and current medications were recorded. Disease activity was assessed before treatment (after 2 weeks of screening observation); after 2, 4, 8, 12, and 16 weeks of treatment; and in the event that treatment was discontinued. Efficacy was not evaluated after the discontinuation of treatment in patients who withdrew from the study before week 16 . At each visit, a physical examination, quality-of-life assessment, laboratory tests, and a global evaluation were conducted, and patients were asked whether any adverse events had occurred. No medications for Crohn's disease other than prednisone, the study drug, and antidiarrheals (loperamide, diphenoxylate, or opiates) were allowed.

Quality of life was assessed with the self-administered Inflammatory Bowel Disease Questionnaire (IBDQ), a previously validated instrument with 4 parts (bowel function, emotional status, systemic symptoms, and social function); the total score on this index ranges from 32 to 224, with higher scores indicating better quality of life. The scores of patients in remission usually range from 170 to 190.22
Patients recorded on diary cards their intake of study medication and prednisone, the frequency of loose stools, the extent of their abdominal pain, and general well-being during the 7 days before each visit. Blood samples were taken for hematologic and biochemical assessments and liver function tests. Blood was drawn for measurement of RBC TPMT enzyme activity at the screening visit (M ayo M edical Laboratories, Rochester, MN). The activity of the TPMT enzyme is subject to significant genetic variation..$^{15}$ There is a trimodal distribution of TPMT activity in the general population: low TPMT activity $(<5.0 \mathrm{U} / \mathrm{mL} \mathrm{RBC})$ occurs at a frequency of $0.3 \%$; intermediate TPMT activity (5.0-13.7 U/mL RBC) occurs at a frequency of $11.1 \%$; and high or normal TPMT activity (13.8-25.1 U/mL RBC) occurs at a frequency of $88.6 \% .{ }^{15}$ Blood was al so drawn for measurement of the active metabolite of AZA, $6 T G N$, in RBCs. The total RBC $6 T G N$ concentration is based on the conversion of $6 \mathrm{TGN}$ to the free 6TGN base, which is then oxidized to a fluorescent sulfonate and assayed by high-performance liquid chromatography. ${ }^{13,23}$ The intracel lular 6T GN concentration thus represents the total RBC $6 T$ GN contents consisting of a composite of the mono-, di-, and triphosphate nucleotides. The RBC 6TGN concentration is normalized to $8 \times 10^{8} \mathrm{RBCs}$. The assay is sensitive to 30 pmol with an overall interday coefficient of variance of $5 \%$, as described previously. ${ }^{13}$ The therapeutic range for RBC $6 T$ GN in patients treated with AZA is unknown.

All adverse events were recorded, whether or not they were related to the study medication. A serious adverse event was defined as one that was life threatening or led to permanent disability, hospitalization, or death. The intensity of adverse events was graded as mild, moderate, or severe, with a severe event considered to be one that was incapacitating, leading to an inability to work or take part in normal activities.

\section{Statistical Analysis}

We estimated that 36 patients were needed in each group to detect an absolute difference of 35\% between groups in the proportion of patients in complete remission, assuming complete remission rates of $60 \%$ with IV AZA treatment compared with $25 \%$ with standard oral AZA, and $80 \%$ power. We planned to recruit a total of 90 patients to allow for a dropout rate of up to $20 \%$.

The primary outcome was the rate of complete remission, defined as a CDAI score $<150$ points and total steroid withdrawal at week 8 . The primary intention-to-treat population (as stated in the study protocol) included all patients who received at least one dose of study medication. Secondary end points were clinical remission (defined as a CDAI score $<150$ points), clinical improvement (defined as a CDAI score $<150$ points or total steroid withdrawal), clinical improvement (defined as a decrease in baseline CDAI $\geq 70$ points), mean daily prednisone dose, mean CDAI scores, mean IBDQ scores, mean RBC 6TGN concentrations, mean white blood cell (W BC) concentrations, and adverse events.

The rates of complete remission were compared using a $\mathrm{M}$ antel- $\mathrm{H}$ aenszel $\chi^{2}$ test controlling for geographic cluster. 
Clusters were used to ensure adequate representation across treatment groups and to minimize disproportionate influence by any given center. Comparisons of more than 2 rates were made using an extended $\mathrm{M}$ antel- $\mathrm{H}$ aenszel test. Clinical remission and adverse event rates were compared using the Fisher exact test. A van Elteren test was use to compare the medians for CDAI scores, IBDQ scores, daily prednisone use, RBC 6TGN concentrations, and W BC concentrations. All tests were two-sided. $P$ values $<0.05$ were considered to indicate statistical significance.

For analysis of remission rates at 8,12 , and 16 weeks, we divided the number of patients in the group who were evaluated and in remission at that time, or who had al ready been withdrawn from the study while in remission, by the number of patients who were evaluated at that time or who had withdrawn before that time (last observation carried forward principle). The secondary end points of clinical remission and the 2 definitions of clinical improvement at 2, 4, 8, 12, and 16 weeks were analyzed similarly. In the analysis of RBC $6 T$ GN and $W B C$ concentrations, data on patients who were lost to follow-up or withdrawn from the study because of deterioration in their condition or adverse events were censored at the time of the last study visit.

\section{Results}

A total of 96 patients were enrolled; 51 were randomly assigned to receive IV AZA and 45 were assigned to receive placebo. All patients received the IV study medication and were included in the intention-totreat analysis. The baseline characteristics of the 2 groups of patients were similar (Table 1). Thirty-two patients $(63 \%)$ in the IV AZA group and 26 patients (58\%) in the placebo group ( $P=0.679$ ) completed the scheduled 16 weeks of treatment and follow-up. Worsening Crohn's disease led to withdrawal of 5 patients in the IV AZA group and 4 patients in the placebo group. Adverse events led to the withdrawal of 8 patients in the IV AZA group and 12 patients in the placebo group. One patient in the IV AZA group declined to continue. Protocol violations led to withdrawal of 3 patients in the IV AZA group and 1 patient in the placebo group. In both groups, 2 patients were withdrawn for other reasons. The median compliance for oral AZA therapy was $96 \%$ in the IV AZA group and $91 \%$ in the placebo group.

\section{Clinical Efficacy}

The rates of complete remission were similar in the IV AZA and placebo groups throughout the study. The respective rates were $25 \%$ and $24 \%(P=0.906)$ after 8 weeks, $22 \%$ and $22 \%$ ( $P=0.939)$ after 12 weeks, and $31 \%$ and $27 \%$ ( $P=0.615$ ) after 16 weeks (Figure 1$)$. Other measures of response including clinical remission and the 2 types of clinical improvement were al so similar
Table 1. Baseline Characteristics of the Patients

\begin{tabular}{|c|c|c|}
\hline Variable & $\begin{array}{l}\text { Placebo group } \\
\quad(n=45)\end{array}$ & $\begin{array}{l}\text { IV AZA group } \\
\quad(n=51)\end{array}$ \\
\hline $\operatorname{Sex}(M / F)$ & $25 / 20$ & $24 / 27$ \\
\hline \multicolumn{3}{|l|}{ Age at entry ( $y r)$} \\
\hline Median & 35 & 33 \\
\hline Range & $19-65$ & $19-63$ \\
\hline \multicolumn{3}{|l|}{ Weight $(k g)$} \\
\hline Median & 68 & 78 \\
\hline Range & $46-110$ & $46-144$ \\
\hline \multicolumn{3}{|l|}{ Duration of disease $(y r)$} \\
\hline Median & 6.6 & 7.1 \\
\hline Range & $0-35$ & $0-28$ \\
\hline \multicolumn{3}{|l|}{$\begin{array}{l}\text { Duration of current exacerbation } \\
\qquad(\mathrm{mo})\end{array}$} \\
\hline Median & 3.2 & 3.8 \\
\hline Range & $0-16$ & $1-51$ \\
\hline \multicolumn{3}{|l|}{ CDAl } \\
\hline Median score & 245 & 244 \\
\hline Range & $142-476$ & $89-424$ \\
\hline \multicolumn{3}{|l|}{ IBDQ } \\
\hline Median score & 123 & 127 \\
\hline Range & $77-182$ & $73-183$ \\
\hline \multicolumn{3}{|l|}{ TPMT activity $(U / m L)$} \\
\hline Median & 17.9 & 19.8 \\
\hline Range & $14-36$ & $14-28$ \\
\hline \multicolumn{3}{|l|}{ Disease site (no. of patients) } \\
\hline Ileum & 8 & 17 \\
\hline Ileocolon & 27 & 27 \\
\hline Colon & 10 & 7 \\
\hline \multicolumn{3}{|l|}{ Previous intestinal resection (no. } \\
\hline of patients) & 26 & 16 \\
\hline Cigarette smoker (no. of patients) & 16 & 22 \\
\hline \multicolumn{3}{|l|}{ Duration of steroid use (days) } \\
\hline Median & 70 & 70 \\
\hline Range & $29-7300$ & $3-330$ \\
\hline
\end{tabular}

in the IV AZA and placebo groups throughout the study. The respective rates of clinical remission (CDAI $<150)$, clinical improvement (CDAI $<150$ or total steroid withdrawal), and clinical improvement (decrease in baseline CDAI $\geq 70$ points) after 2, 4, 8, 12, and 16 weeks are shown in Figure 1. The median time to first clinical remission (CDAI < 150) was identical in the IV AZA and placebo groups (28 vs. 28 days; $P=0.984$ ).

The median scores on the CDAI, the IBDQ quality of life index, and the median daily prednisone doses were similar in the IV AZA and placebo groups throughout the 16-week study (Figure 2). The rate of complete remission (CDAI $<150$ and total steroid withdrawal) was not significantly greater in patients in either treatment group who had a shorter duration of steroid therapy ( $\leq 90$ days) than in patients who had a longer duration of steroid therapy ( $\geq 91$ days). The IV AZA and placebo groups were similar with respect to the percentage of patients who had previously been treated with AZA/6M P ( $27 \%$ vs. $16 \%$; $P=0.179$ ), cyclosporine ( $8 \%$ vs. $7 \%$; $P=0.813)$, and methotrexate $(21 \%$ vs. $13 \% ; P=$ 0.410). There were no significant differences in the rates 

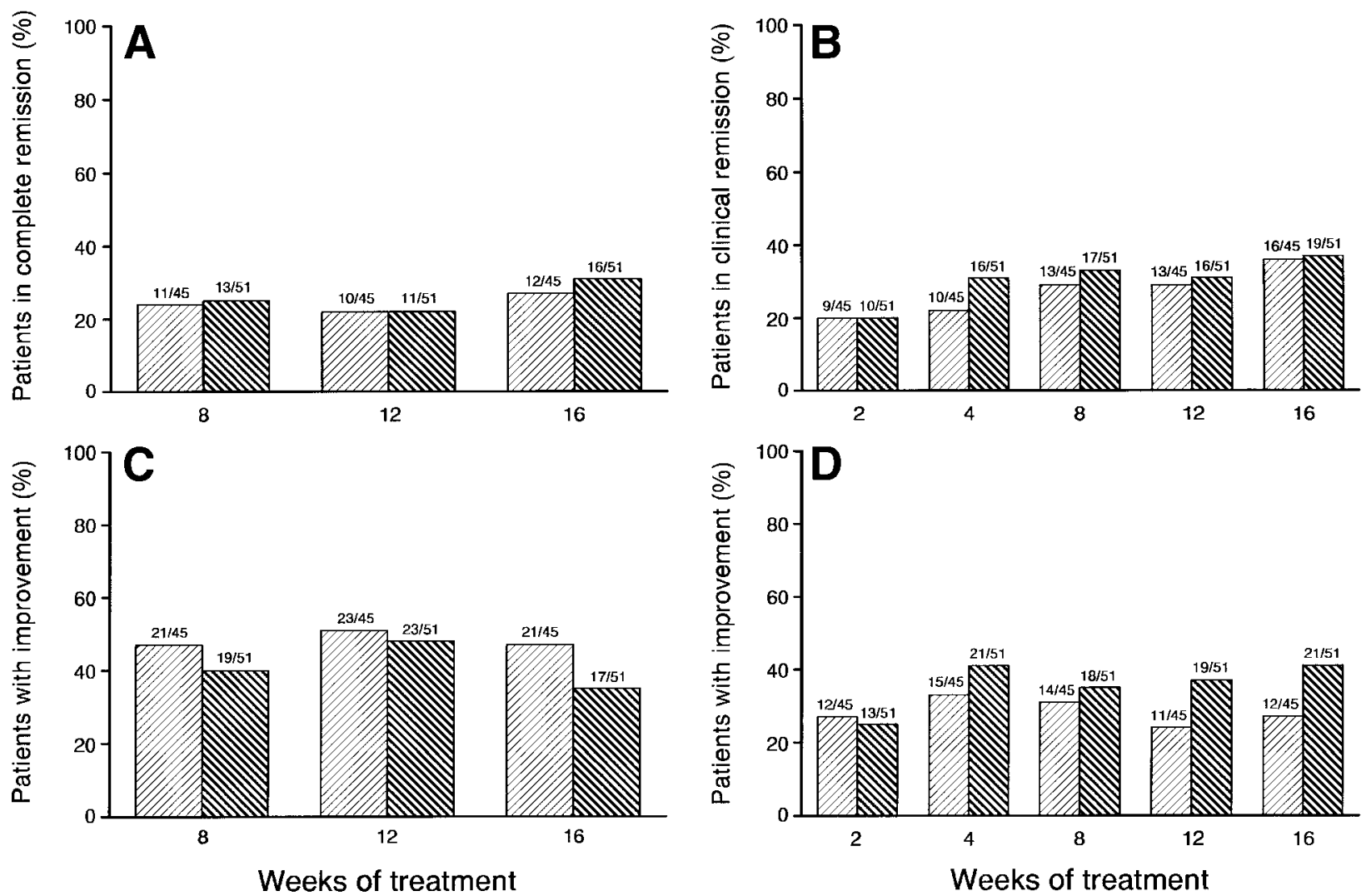

Figure 1. Percentages of patients with Crohn's disease with improvement or remission at each study visit, according to treatment group. $\square$, Placebo; $\mathbb{N}$, IV AZA. There were no significant differences between the 2 groups at any time point. (A) Complete remission (CDAl score $<150$ points and total steroid withdrawal). (B) Clinical remission (CDAl score $<150$ points). (C) Improvement (CDAl score $<150$ points or total steroid withdrawal). (D) Improvement (decrease in CDAl score from baseline $\geq 70$ points).

of complete remission in the IV AZA and placebo groups when stratified according to previous therapy with AZA/6M P, cyclosporine, or methotrexate.

Azathioprine Dose, 6TGN Concentrations, TPMT Activity, and WBC Concentrations

The median baseline RBC TPMT activities were similar in the IV AZA and placebo groups (Table 1). The median RBC 6TGN concentrations were significantly greater at the end of the 36-hour infusion (week 0.2) and at week 1 in the IV AZA group but were similar at all other time points throughout the 16-week study (Figure 2). The overall mean daily doses of oral $A Z A$ in the IV AZA and placebo groups $(2.00 \pm 0.31$ and $2.15 \pm 0.24$ $\mathrm{mg} / \mathrm{kg}$, respectively) were associated with overall mean RBC $6 T$ T N concentrations using within subject means of $164 \pm 61$ and $124 \pm 67 \mathrm{pmol} / 8 \times 10^{8} \mathrm{RBCs}$. The correl ation between the baseline TPM T activities and the mean within subject RBC 6T GN concentrations over 16 weeks in the combined patient groups was $r=-0.0137$, $\mathrm{P}=0.8975$. The rate of complete remission (CDAI < 150 and total steroid withdrawal) was not significantly greater in patients with $6 \mathrm{TGN}$ concentrations of $\geq 200$ $\mathrm{pmol} / 8 \times 10^{8} \mathrm{RBCs}$.
The mean total WBC concentrations were significantly lower at weeks 1 and 2 in the IV AZA group than in the placebo group but were otherwise similar throughout the 16-week study (Figure 2). The correlation between the total W BC concentrations and the corresponding RBC 6TGN concentrations in each patient in the combined patient groups over weeks 1-16 was $r=$ $-0.11, P=0.30$. The rate of complete remission (CDAI $<150$ and total steroid withdrawal) was not significantly greater in patients with mild leukopenia (defined as a total W BC concentration $\leq 5.0 \times 10^{8} / \mathrm{L}$ ).

\section{Adverse Events}

The numbers of patients with adverse events were similar in the 2 groups, with the exception of nausea and infusion site reactions, which were more common in the IV AZA group; the most frequent adverse events and adverse events known to be associated with AZA are shown in Table 2. Serious adverse events and severe adverse events were also similar in both groups. Aside from the decrease in the mean total W BC concentrations in the IV AZA group at weeks 1 and 2 (discussed above), there were no clinically significant changes in any other hematologic or biochemical variables in either group. 

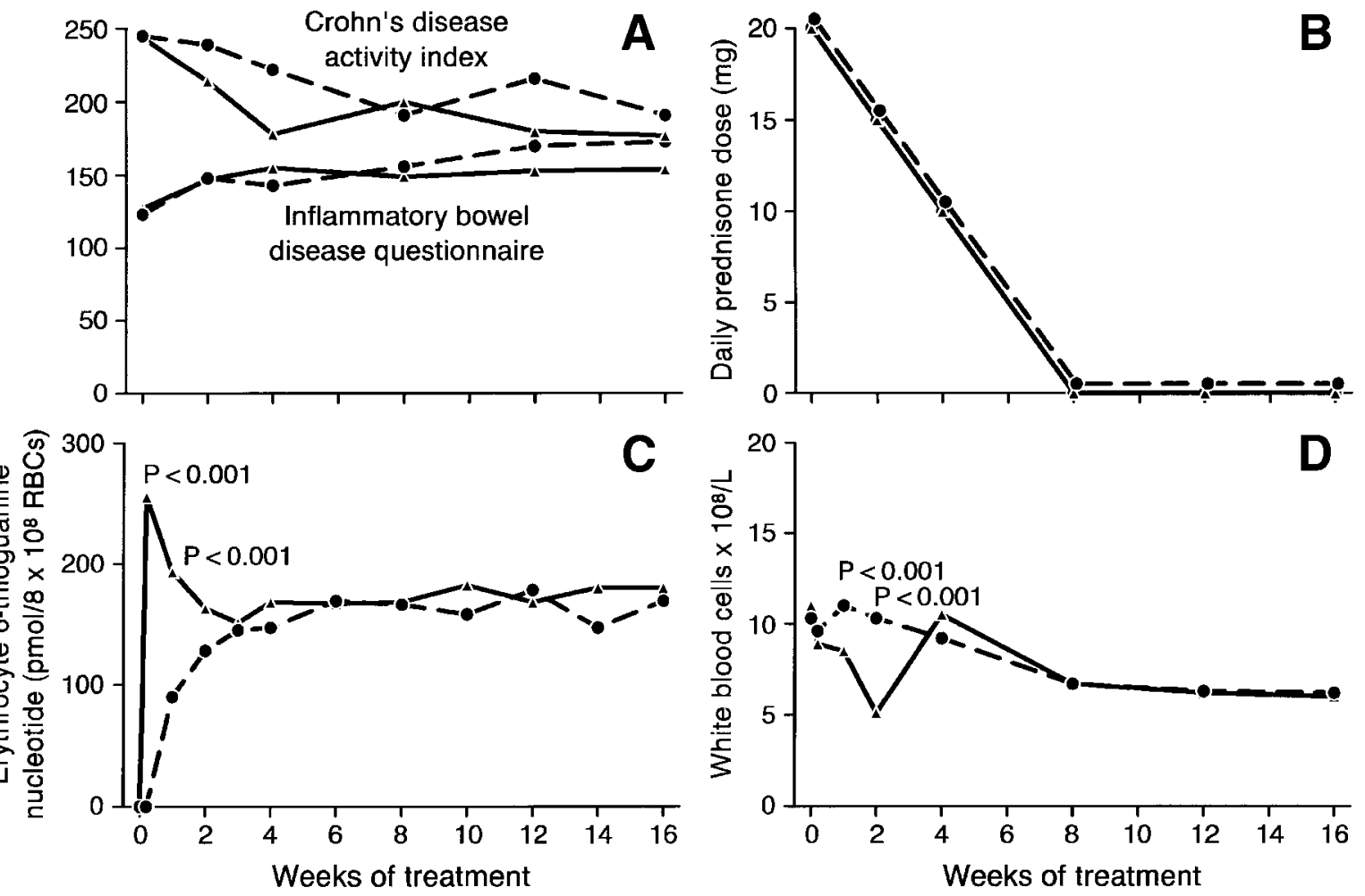

Figure 2. Median scores or values at each study visit according to treatment group. $\bullet$, Placebo; $\boldsymbol{\Delta}$, IV AZA. The only significant differences between the 2 groups at any of the time points are those indicated in the figure. (A) CDAl and IBDQ quality of life index. (B) Prednisone dose. (C) RBC 6TGN nucleotide concentrations. (D) Total WBC concentrations.

Table 2. Adverse Events in the Two Treatment Groups

\begin{tabular}{|c|c|c|c|}
\hline Variable & $\begin{array}{l}\text { Placebo } \\
\text { group } \\
(n=45)\end{array}$ & $\begin{array}{l}\text { IV AZA } \\
\text { group } \\
(n=51)\end{array}$ & $\begin{array}{c}P \\
\text { value }\end{array}$ \\
\hline No. of adverse events & 185 & 258 & 0.730 \\
\hline No. of patients with adverse events & 40 (89\%) & 47 (92\%) & 0.730 \\
\hline $\begin{array}{l}\text { No. of patients with serious adverse } \\
\text { events }\end{array}$ & $11(24 \%)$ & $13(25 \%)$ & 1.000 \\
\hline $\begin{array}{l}\text { No. of patients with severe adverse } \\
\text { events } \\
\text { Most frequent adverse events (no. of } \\
\text { events) }\end{array}$ & $14(31 \%)$ & $19(37 \%)$ & 0.667 \\
\hline Nausea & $15(33 \%)$ & $28(55 \%)$ & 0.041 \\
\hline Injection site reaction & $1(2 \%)$ & $11(22 \%)$ & 0.005 \\
\hline Headaches & $10(22 \%)$ & $7(14 \%)$ & 0.298 \\
\hline Malaise and fatigue & $9(20 \%)$ & $8(16 \%)$ & 0.604 \\
\hline Vomiting & $8(18 \%)$ & $9(18 \%)$ & 1.000 \\
\hline Viral lower respiratory infection & $6(13 \%)$ & $6(12 \%)$ & 1.000 \\
\hline Abdominal pain & $5(11 \%)$ & $5(10 \%)$ & 1.000 \\
\hline Arthralgias & $3(7 \%)$ & $5(10 \%)$ & 0.719 \\
\hline \multicolumn{4}{|l|}{$\begin{array}{l}\text { Adverse events commonly associated } \\
\text { with AZA (no. of events) }\end{array}$} \\
\hline Leukopenia $^{a}$ & $5(11 \%)$ & $5(10 \%)$ & 1.000 \\
\hline Pneumonia & $2(4 \%)$ & $0(0 \%)$ & 0.217 \\
\hline Thrombocytopenia & $0(0 \%)$ & $2(4 \%)$ & 0.497 \\
\hline Pancreatitis & $2(4 \%)$ & $0(0 \%)$ & 0.497 \\
\hline Abnormal liver function tests & $1(2 \%)$ & $0(0 \%)$ & 0.469 \\
\hline Fever & $4(9 \%)$ & $4(8 \%)$ & 1.000 \\
\hline Rash & $2(4 \%)$ & $3(6 \%)$ & 1.000 \\
\hline
\end{tabular}

${ }^{a}$ Clinically significant leukopenia defined as a total WBC $<3.0 \times$ $10^{8} / \mathrm{L}$.

\section{Discussion}

We found that administration of a loading dose of IV AZA does not decrease the timeto response or increase the response rate in patients with active steroid-treated Crohn's disease beginning oral AZA treatment. The condition of patients in both groups improved after 2 weeks and reached a plateau after 4 weeks. The degree of response was similar in the 2 groups throughout the study, as measured by complete remission, clinical remission, and the 2 types of clinical improvement. Other measures of response, such as a decrease in mean daily prednisone dose and an increased quality of life, also showed a similar degree of improvement in the 2 groups throughout the study. The duration of prestudy steroid therapy had no effect on response. The relatively high rates of early withdrawal ( $37 \%$ for the IV AZA group and $42 \%$ for the placebo group) are similar to those in other studies of medical therapy for active Crohn's disease. ${ }^{16-18,21}$ Given the size of this study and the comprehensive nature of the outcome measures, it is unlikely that a clinically important benefit went undetected. Based on these findings, we do not recommend the use of an IV loading dose of AZA in patients with Crohn's disease who are beginning oral AZA treatment.

One assumption that our study was based on is that AZA and 6MP have a slow onset of action. The results of 
the study suggest that this assumption may be incorrect and that the evidence underlying this belief should be reexamined. The results from 3 placebo-controlled trials of oral AZA for active Crohn's disease published in the early 1970 s can probably be dismissed as invalid because of methodological problems including small sample size, crossover design, and use of unvalidated end points. ${ }^{1,24,25}$ In 1980, Present et al. ${ }^{4}$ reported a placebo-controlled trial showing that oral 6MP was effective for active Crohn's disease. Although this important study establi shed a role for 6MP/AZA in the treatment of Crohn's disease, methodological problems including a heterogenous patient population, crossover design, use of unval idated end points, and infrequent assessments of clinical response make poststudy subgroup analyses and observations suspect. In particular, the authors' assertion that the mean time to response was 3.1 months may represent an overestimate because patients were only clinically assessed every 3 months. Two other placebo-controlled studies of oral AZA or 6MP failed to show efficacy at week 12 but did show efficacy at 12-15 months. ${ }^{6,7}$ In these studies, initial combination therapy with high-dose corticosteroids, which was tapered slowly over 12 weeks or more, makes it difficult to determine the time to response for $A Z A / 6 M P$. In the $\mathrm{N}$ ational Cooperative Crohn's Disease Study, monotherapy with oral AZA was compared with placebo. ${ }^{26}$ There was a trend toward a benefit for AZA-treated patients that did not reach statistical significance. The maximum decrease in the mean CDAI score for the AZA-treated patients occurred at 9 weeks. In another study, oral AZA administered in combination with high-dose corticosteroids (which were rapidly tapered to $10 \mathrm{mg} /$ day over 6 weeks) showed a significant benefit for AZA by week $8 .{ }^{5}$ Finally, our study showed that patients in the placebo group (who were beginning standard oral AZA therapy) reached a plateau of the proportion of patients who experienced a clinical response after 4 weeks. These findings suggest that oral AZA or 6MP may act more rapidly than previously bel ieved, perhaps over 4-8 weeks.

Without a placebo control group, it is difficult to directly compare the complete remission rates in our study (31\% for the IV AZA group and $27 \%$ for the standard oral AZA group at 16 weeks) with those of other controlled trials of oral AZA for active Crohn's disease. $\mathrm{N}$ evertheless, the remission rates in our study seem to be generally lower than those previously reported. ${ }^{8}$ The likely explanation is that the patients entering our trial were steroid refractory and that we required complete steroid withdrawal as part of the definition of remission. The remission rates in our study seem similar to 2 other recent trials of methotrexate and infliximab for active
Crohn's disease refractory to steroids and other medical therapies. ${ }^{21,27}$

A nother assumption that our study was based on is that 6TGN accumulates slowly in RBCs and other body tissues, and prolonged treatment with oral $A Z A / 6 M P$ is required to reach steady state. The results of our study indicate that this assumption is incorrect. We showed that steady-state concentrations of RBC 6TGN were achieved by 2 weeks in patients in the placebo group who were beginning standard oral AZA treatment. Although the mean RBC 6TGN concentrations were significantly higher in the IV AZA group at weeks 0.2 and 1, they were similar beginning at week 2 for the remainder of the 16-week study. O ur results corroborate the findings of 2 other pharmacokinetic studies in patients with acute lymphoblastic leukemia or renal allografts treated with 6MP or AZA in which RBC 6TGN concentrations were reported to reach steady state in 14-21 days. ${ }^{11,12}$ These findings show that patients with active Crohn's disease treated with oral $A Z A$ reach steady-state concentrations of RBC TGN over 2-3 weeks.

Our study does not clarify the clinical use of measuring the activity of the major catabolic enzyme of AZA (RBC TPMT) before starting oral AZA therapy and of doing therapeutic drug monitoring with RBC 6T GN concentrations during oral AZA therapy. Patients were eligible for our study only if they had normal RBC TPMT activity, leading to a relatively homogenous and low-risk patient population. There was not a statistically significant inverse correlation between baseline RBC TPMT activity and mean within subject RBC 6T G N concentrations over 16 weeks. A $n$ inverse relationship would likely have been shown if patients with intermediate and homozygous low TPMT activity had been included, similar to previous reports in children with acute lymphoblastic leukemi $a^{28}$ and adults with rheumatoid arthritis. ${ }^{29}$ We did not find that RBC 6 T GN concentrations of $\geq 200 \mathrm{pmol} / 8 \times 10^{8}$ RBCs were associated with a greater likelihood of response. These findings are in contrast to a prior report suggesting a correlation between clinical response and RBC 6TGN in patients with Crohn's disease treated with a range of $6 \mathrm{MP}$ doses.30 The average RBC $6 \mathrm{TGN}$ concentrations over 16 weeks in our patients treated with IV placebo followed by $2 \mathrm{mg} / \mathrm{kg}$ oral AZA were relatively low (mean, $124 \mathrm{pmol} / 8 \times 10^{8} \mathrm{RBCs}$ ) compared with concentrations reported in patients with acute lymphoblastic leukemia treated with $75 \mathrm{mg} / \mathrm{m}^{2}$ oral $6 \mathrm{MP}$ (median, $\left.284 \mathrm{pmol} / 8 \times 10^{8} \mathrm{RBCS}\right){ }^{31}$ To further explore the potential use of RBC 6TGN therapeutic drug monitoring in patients treated with oral AZA, additional studies including patients with intermediate or homozygous low 
TPMT activity and exploring a range of oral AZA doses (perhaps 0.5-4.0 mg/kg) should be undertaken.

There was a significant but transient decrease in the mean total W BC concentration in the IV AZA group at weeks 1 and 2; otherwise both study groups had a paral lel decrease in the mean total WBC concentration that plateaued at week 8. Ten percent of patients in the IV AZA group developed clinically significant leukopenia (total W BC $<3.0 \times 10^{8} / \mathrm{L}$ ) during the study compared with $11 \%$ in the placebo group. The rate of leukopenia in the placebo group (standard oral AZA) is similar to the leukopenia rates of $2 \%-11 \%$ reported in other safety studies of AZA and 6MP in patients with IBD. ${ }^{32-34}$ There was not a statistically significant inverse correla tion between the total WBC concentrations and the corresponding RBC 6TGN concentrations over weeks 1-16. An inverse relationship would likely have been shown if patients with intermediate or homozygous low TPM T activity and a wider range of AZA doses had been included, similar to a previous report in children with acute lymphoblastic leukemia. ${ }^{35}$ We were not able to identify a cutoff value for the RBC 6TGN concentration that accurately predicted leukopenia. A retrospective study suggested an association between mild leukopenia (defined as a total W BC concentration $\leq 5.0 \times 10^{8} / \mathrm{L}$ ) and remission in patients with Crohn's disease treated with $6 \mathrm{M} \mathrm{P}^{36}$ In our study, the rate of complete remission (CDAI $<150$ and total steroid withdrawal) was not significantly greater in patients with mild leukopenia; we are therefore unable to confirm to the previous associa tion.

AZA therapy was generally well tolerated in both patient groups, and the frequency and type of AZAassociated adverse events observed were similar to those reported in other studies. ${ }^{32-34}$ The frequency of severe and serious adverse events (according to W orld $\mathrm{H}$ ealth Organization definitions) was relatively high, but generally comparable with other studies of medical therapy for active Crohn's disease. ${ }^{17,18,21,27}$ The serious adverse events were all related to need for hospitalization, in most cases because of worsening of Crohn's disease. O ur results show that pretreatment with an IV AZA loading dose before beginning oral $A Z A$ treatment, although not of clinical benefit, is as safe as standard treatment with oral AZA in patients with normal RBC TPMT activity.

In conclusion, a loading dose is safe but not effective in decreasing the time to response in patients with steroidtreated Crohn's disease beginning AZA treatment. Steadystate concentrations of R BC 6TGN and clinical improvement/remission in patients receiving standard oral $A Z A$ occurred earlier than previously reported. Additional studies to explore the time to response, the dose response, and the clinical use of therapeutic drug monitoring in patients with Crohn's disease treated with oral AZA are warranted.

\section{References}

1. Willoughby JMT, Kumar PJ, Beckett J, Dawson AM. Controlled trial of azathioprine in Crohn's disease. Lancet 1971;2:944-947.

2. Rosenberg JL, Levin B, Wall AJ, Kirsner JB. A controlled trial of azathioprine in Crohn's disease. Dig Dis 1975;20:721-726.

3. O'Donoghue DP, Dawson AM, Powell-Tuck J, Brown RL, LennardJones JE. Double-blind withdrawal trial of azathioprine as maintenance treatment for Crohn's disease. Lancet 1978;2:955-957.

4. Present DH, Korelitz BI, Wisch N, Glass JL, Sachar DB, Pasternack BS. Treatment of Crohn's disease with 6 -mercaptopurine: a long-term, randomized, double-blind study. N Engl J Med 1980;302: 981-987.

5. Ewe K, Press AG, Singe CC, Stufler M, Ueberschaer B, Hommel G, Buschenfelde KHMZ. Azathioprine combined with prednisolone or monotherapy with prednis one in active Crohn's disease. Gastroenterology 1993;105:367-372.

6. Candy S, Wright J, Gerber M, Adams G, Gerig M, Goodman R. A controlled double blind study of azathioprine in the management of Crohn's disease. Gut 1995;37:674-678.

7. Markowitz J, Grancher K, Mandel F, Daum F, and the 6MP Collaborative Group. 6-Mercaptopurine (6MP) + prednisone therapy for newly diagnosed pediatric Crohn's disease (CD): a prospective, multicenter, placebo-controlled clinical trial (abstr). Gastroenterology 1998;114:A1032.

8. Pearson DC, May GR, Fick GH, Sutherland LR. Azathioprine and 6 -mercaptopurine in Crohn's disease: a meta-analysis. Ann Intern Med 1995;122:132-142.

9. Lennard L, Brown CB, Fox M, Maddocks J L. Azathioprine metabolism in kidney transplant recipients. Br J Clin Pharmacol 1984;18: 693-700.

10. Chan GLC, Erfmann GR, Gruber SA, Matas AJ, Canafax DM. Azathioprine metabolism: pharmacokinetics of 6-mercaptopurine, 6-thioguanine, 6-thiouric acid and 6-thioguanine nucleotides in renal transplant patients. J Clin Pharmacol 1990;30:358-363.

11. Lennard L, Lilleyman JS. Variable mercaptopurine metabolism and treatment outcome in childhood lymphoblastic leukemia. J Clin Oncol 1989;7:1816-1823.

12. Bergan S, Rugstad HE, Bentdal O, Endresen L, Stokke O. Kinetics of mercaptopurine and thioguanine nucleotides in renal transplant recipients during azathioprine treatment. Ther Drug Monit 1994;16:13-20.

13. Sandborn WJ, Van Os EC, Zins BJ, Tremaine WJ, Mays DC, Lipsky JJ. An intravenous loading dose of azathioprine decreases the time to response in patients with Crohn's disease. Gastroenterology 1995;109:1808-1817.

14. Best WR, Becktel J N, Singleton JW. Rederived values of the eight co-efficients of the Crohn's disease activity index (CDAI). Gastroenterology 1979;77:843-846.

15. Weinshilboum RN, Sladek SL. Mercaptopurine pharmacogenetics: monogenic inheritance of erythrocyte thiopurine methyltransferase activity. Am J Hum Genet 1980;32:651-662.

16. Singleton JW, Hanauer SB, Gitnick GL, Peppercorn MA, Robinson MG, Wruble LD, Krawitt EL, and the Pentasa Crohn's Disease Study Group. Mesalamine capsules for the treatment of active Crohn's disease: results of a 16-week trial. Gastroenterology 1993;104:1293-1301.

17. Greenberg GR, Feagan BG, Martin F, Sutherland LR, Thomsen ABR, Williams CN, Nilsson LG, Persson $T$, and the Canadian Inflammatory Bowel Disease Study Group. Oral budesonide for active Crohn's disease. N Engl J Med 1994;331:836-841. 
18. Thomsen 00, Cortot A, J ewell D, Wright JP, Winter T, Veloso FT, Vatn M, Persson T, Petterss on E, for the International BudesonideMesalamine Study Group. A comparison of budesonide and mesalamine for active Crohn's disease. N Engl J Med 1998;339: 370-374

19. Zimm S, Ettinger LJ, Locenberg JS, Kamen BA, Vietti TJ, Belasco J, Coglinao-Shutta N, Balis F, Lavi LE, Collins JM, Poplack DG. Phase 1 in a clinical pharmacological study of mercaptopurine administered as a prolonged intravenous infusion. Cancer Res 1985;45:1869-1873.

20. Adamson PC, Zimm S, Ragab AH, Steinberg SM, Balis F, Kamen BA, Vietti TJ, Gillespie A, Poplack DG. A phase II trial of continuous-infusion 6-mercaptopurine for childhood solid tumors. Cancer Chemother Pharmacol 1990;26:343-344.

21. Feagan BG, Rochon J, Fedorak RN, Irvine EJ, Wild G, Sutherland L, Steinhart AH, Greenberg GR, Gillies R, Hopkins M, Hanauer SB, McDonald JWD, for the North American Crohn's Disease Study Group investigators. Methotrexate for the treatment of Crohn's disease. N Engl J Med 1995;332:292-297.

22. Irvine EJ, Feagan B, Rochon J, Archambault A, Fedorak RN, Groll A, Kinnear D, Saibil F, McDonald JWD, for the Canadian Crohn's Relapse Prevention Trial. Quality of life: a valid and reliable measure of therapeutic efficacy in the treatment of inflammatory bowel disease. Gastroenterology 1994;106:287-296.

23. Erdmann GR, France LA, Bostrom BC, Canafax DM. A reversedphase high-performance liquid chromatography approach in determining total red blood cell concentrations of 6-thioguanine, 6-mercaptopurine, methylthioguanine, and methylmercaptopurine in a patient receiving thiopurine therapy. Biomed Chromatogr 1990;4:47-51.

24. Rhodes J, Bainton D, Beck P, Campbell H. Controlled trial of azathioprine in Crohn's disease. Lancet 1971;2:1273-1276.

25. Klein M, Binder HJ, Mitchell M, Aaronson R, Spiro H. Treatment of Crohn's disease with azathioprine: a controlled evaluation. Gastroenterology 1974;66:916-922.

26. Summers RW, Switz DN, Sessions JT, Becktel J N, Best WR, Kern F, Singleton JW. National cooperative Crohn's disease study: results of drug treatment. Gastroenterology 1979;77:847-869.

27. Targan SR, Hanauer SB, van Deventer SJH, Mayer L, Present DH, Braakman TAJ, DeWoody KL, Schaible TF, Rutgeerts $P$, and the Crohn's Disease CA2 Study Group. A short-term study of chimeric monoclonal antibody CA2 to tumor necrosis factor $\alpha$ for Crohn's disease. N Engl J Med 1997;337:1029-1035.

28. Lennard L, Lilleyman JS, Van Loon J, Weinshilboum RN. Genetic variation in response to 6 -mercaptopurine for childhood acute lymphoblastic leukaemia. Lancet 1990;336:225-229.

29. Black AJ, McLeod HL, Capell HA, Powrie RH, Matowe LK, Pritchard SC, Collie-Duguid ESR, Reid DM. Thiopurine methyltransferase genotype predicts therapy-limiting severe toxicity from azathioprine. Ann Intern Med 1998;129:716-718.

30. Cuffari C, Theoret Y, Latour S, Seidman G. 6-Mercaptopurine metabolism in Crohn's disease: correlation with efficacy and toxicity. Gut 1996;39:401-406.

31. Lilleyman JS, Lennard L. Mercaptopurine metabolism and the risk of relapse in childhood lymphoblastic leukaemia. Lancet 1994; 343:1188-1190.

32. Present DH, Meltzer SJ, Krumholz MP, Wolke A, Korelitz BI. 6-mercaptopurine in the management of inflammatory bowel disease: short- and long-term toxicity. Ann Intern Med 1989;111: 641-649.

33. Connell WR, Kamm MA, Ritchie JK, Lennard-Jones JE. Bone marrow toxicity caused by azathioprine in inflammatory bowel disease: 27 years experience. Gut 1993;34:1081-1085.

34. Kirschner BS. Safety of azathioprine and 6-mercaptopurine in pediatric patients with inflammatory bowel disease. Gastroenterology 1998;115:813-821.

35. Lennard L, Rees CA, Lilleyman JS, Maddocks JL. Childhood leukemia: a relationship between intracellular 6-mercaptopurine metabolites and neutropenia. Br J Clin Pharmacol 1983;16:359363.

36. Colonna T, Korelitz BI. The role of leukopenia in the 6 -mercaptopurine-induced remission of refractory Crohn's disease. Am J Gastroenterol 1994;89:362-366.

Received January 7, 1999. Accepted May 19, 1999.

Address requests for reprints to: William J. Sandborn, M.D., Mayo Clinic, 200 First Street Southwest, Rochester, Minnesota 55905. Fax: (507) 266-0335.

Supported by a research grant from Glaxo Wellcome, Research Triangle Park, North Carolina.

Presented at the World Congress of Gastroenterology, September 7, 1998, in Vienna, Austria, and the annual meeting of the American College of Gastroenterology, October 13, 1998, in Boston, Massachusetts.

Investigators in the study group are as follows: Jeffery Breiter, M.D., Manchester, CT; Charles O. Elson, M.D., and C. Mel Wilcox, M.D., Division of Gastroenterology, University of Alabama, Birmingham, AL; Susan Gordon and Robert H. Murdock, Jr., Ph.D., GI Medical Affairs, and Christi S. Kleoudis, M.P.H., Section of Biostatistics, Glaxo Wellcome, Research Triangle Park, NC; Brian G. Feagan, M.D., and John W. D. McDonald, M.D., Division of Gastroenterology, University of Western Ontario, London, Ontario, Canada; Richard N. Fedorak, M.D., Division of Gastroenterology, University of Alberta, Edmonton, Alberta, Canada; Stephen B. Hanauer, M.D., Division of Gastroenterology, University of Chicago, Chicago, IL; Kim L. Isaacs, M.D., Ph.D., Division of Gastroenterology, University of North Carolina, Chapel Hill, NC; Richard Kozarek, M.D., Division of Gastroenterology, Virginia Mason Clinic, Seattle, WA; James J. Lipsky, M.D., Dennis C. Mays, Ph.D., and M. Gennette Pike, B.A., Clinical Pharmacology Unit, and William J. Sandborn, M.D., and William J. Tremaine, M.D., Division of Gastroenterology, Mayo Clinic, Rochester, MN; Paul Maton, M.D., Oklahoma Foundation for Digestive Research, Oklahoma City, OK; Daniel H. Present, M.D., and David Sachar, M.D., Division of Gastroenterology, Mount Sinai School of Medicine, New York, NY; Charles A. Sninsky, M.D., and John Valentine, M.D., Division of Gastroenterology, University of Florida, Gainesville, FL; Lloyd R. Sutherland, M.D., Division of Gastroenterology, University of Calgary, Calgary, Alberta, Canada; Stephan R. Targan, M.D., and Eric Vasiliauskas, M.D., Division of Gastroenterology, Cedars Sinai Medical Center, Los Angeles, CA; Douglas C. Wolf, M.D., Atlanta Gastroenterology Associates, Atlanta, GA; Andrew Warner, M.D., Division of Gastroenterology, Lahey Clinic, Burlington, MA; and Lawrence D. Wruble, M.D., Memphis Gastroenterology Group, Memphis, TN. 